\title{
Psychiatric disorders in women prisoners who have engaged in near-lethal self-harm: case-control study
}

\author{
Lisa Marzano, Seena Fazel, Adrienne Rivlin and Keith Hawton
}

\section{Background}

Female prisoners are 20 times more likely to die by suicide than women of the same age in the general population. However, risk factors and indicators of vulnerability for suicide in this group are not well-known.

\section{Aims}

We investigated prevalence of psychiatric disorders in women prisoners who had recently engaged in near-lethal self-harm (cases) and others who had never carried out near-lethal attempts in prison (controls)

\section{Method}

We interviewed 60 cases and 60 controls from all closed female prison establishments in England and Wales. In addition to gathering details of sociodemographic,

criminological and clinical history, we assessed participants' current and lifetime disorders using the Mini-International Neuropsychiatric Interview. Associations between near-lethal self-harm and psychiatric disorders were adjusted for age, educational qualifications (any $v$. none) and remand status (sentenced $v$. unsentenced).

\section{Results}

At the time of their near-lethal self-harm, 53 cases (88\%) were on ACCT (Assessment, Care in Custody and Teamwork), the system for the care of prisoners at risk of suicide and self-harm in England and Wales. Cases had significantly greater levels of psychiatric morbidity than controls, and more comorbidity. The strongest associations with near-lethal self-harm were with current depression (ageadjusted odds ratio $(\mathrm{OR})=23.7,95 \% \mathrm{Cl}$ 9.0-62.3), the presence of two or more diagnoses (age-adjusted OR $=18.3$, 95\% Cl 5.9-56.9), a history of psychiatric in-patient treatment $(\mathrm{OR}=25.4,95 \% \mathrm{Cl}$ 5.7-113.5) and previous attempted suicide, especially in prison (OR $=129,95 \% \mathrm{Cl} 27-611)$. The only tested diagnoses not associated with near-lethal self-harm were antisocial personality disorder, substance use and eating disorders. Adjusting for sociodemographic and criminological variables did not significantly alter any of these findings.

\section{Conclusions}

This research underlines the importance of psychiatric risk factors for suicide in custody and in particular comorbidity. The finding that a formal care plan was in place for most cases at the time of their near-lethal act is indicative of good risk detection, but also suggests high levels of unmet need. Given the potential complexity of their mental health needs, interventions incorporating pharmacological and psychological treatments should be considered for at-risk prisoners

\section{Declaration of interest}

None.
Suicide is a leading cause of death in prisons in most Western countries. ${ }^{1-3}$ In England and Wales, between 1978 and 2003 the age-standardised suicide rate in female prisoners was 20 times higher than in women in the general population. ${ }^{4}$ It has been suggested that this could be the result of high levels of mental health and substance misuse problems in women prisoners, ${ }^{5-8}$ which are risk factors for suicide in the general population., ${ }^{9,10}$ In one of the few studies to have focused specifically on suicide among female prisoners, higher rates of mental health problems were found in women prisoners than reported in male prisoners who had died by suicide. ${ }^{11}$ However, lack of a control group in this and similar studies means that it is not known whether levels of psychiatric morbidity in female prisoners who have died by suicide differ from other female prisoners. Also, despite numerous studies pointing to psychiatric disorder as a risk factor for suicide in prisoners, ${ }^{12,13}$ previous research has been in male-only or predominantly male samples, has mostly lacked power to investigate specific diagnostic categories, and reported insufficient detail to enable reliable assessment of the contribution of psychiatric comorbidity. A recent systematic review of risk factors for suicide in prison found no clinical studies specifically on women. $^{14}$

In this study we aimed to address these limitations by investigating the prevalence of psychiatric disorders in women prisoners who had nearly died as a result of a suicide attempt compared with female prisoners who had never made a near-lethal attempt in prison. Previous studies have consistently reported high rates of self-harm, suicidal ideation and suicide attempts in women prisoners, both in their lifetime and during the current prison term. ${ }^{15-17}$ With $30 \%$ of female prisoners engaging in self-harm while in prison, ${ }^{18}$ and $5 \%$ having attempted suicide in custody in the past month, ${ }^{19}$ the burden placed on prisons and their mental health services is considerable. In addition, there is evidence that individuals who make medically serious suicide attempts are epidemiologically similar to individuals who complete suicide, ${ }^{20,21}$ and twice as likely as other suicide attempters to die by suicide. ${ }^{22}$ Therefore, as well as presenting an important clinical problem in their own right, near-fatal attempts provide a valid proxy for self-inflicted deaths in research investigating risk factors for suicide. ${ }^{23}$ They enable investigation of factors that require self-report, including personal issues, triggers and psychological mechanisms of which prison authorities and key informants may be unaware, and which are often not reliably recorded in clinical and prison records of prisoners who have taken their own lives. ${ }^{24,25}$ In addition, being a less rare event than prisoner suicide, near-lethal self-harm allows for more adequately powered investigations than studies of the characteristics of prisoners who have died by suicide. 


\section{Method}

\section{Sample and selection criteria}

In consultation with the Ministry of Justice Safer Custody and Offender Policy Group (SCOP), and with approval from the Thames Valley Research Ethics Committee, one of us (L.M.) conducted semi-structured face-to-face interviews with 60 female prisoners over the age of 18 years who had carried out near-lethal suicide attempts, and 60 control prisoners, who had no history of a near-lethal suicide attempt in prison. The total sample size $(n=120)$ was decided a priori based on power calculations. The study drew on earlier pilot work, ${ }^{26}$ and was further piloted with three female forensic patients. The interviewer had training in the use of the Mini-International Neuropsychiatric Interview (MINI) and received fortnightly clinical supervision by a consultant forensic (S.F.) and general adult psychiatrist (K.H.).

Participants were selected from all ten 'closed' female prison establishments in England and Wales. 'Open' establishments, which have lesser security levels and restrictions, were excluded from the study because of their low rates of suicide and suicide attempts. Between November 2007 and October 2008 each establishment was visited every 4 to 6 weeks to identify prisoners who had been involved in an act that: could have been lethal had it not been for intervention or chance; and/or involved methods that are associated with a reasonably high chance of death. These criteria were operationalised to assist prison staff to refer cases suitable for inclusion in the study (Appendix). All prisoners who had carried out a near-lethal attempt within the past month were approached and invited to participate, unless they had already been interviewed.

Controls were selected from prisons of the same security category (but not the exact same prison) and within a 10 -year age range ( 5 years older or younger) of the prisoner who had attempted suicide. They were randomly selected by the Ministry of Justice from the Prison Service's daily list of prisoners. For each near-lethal case, a list of five potential controls was generated, of whom the prisoner closest in age to the case was the first to be approached to participate in the study. In the event that she failed to meet the inclusion criteria, declined to participate or was no longer in custody, a second prisoner was approached. This procedure was repeated until a suitable control prisoner was found.

Eligible cases and controls were excluded from the study if they were not willing to participate, could not speak English, or were deemed to be dangerous or unable to give consent owing to severe mental illness. Based on these criteria, 26 prisoners who had been involved in a near-lethal act were excluded. Eight prisoners declined to take part, five were considered dangerous (in three cases because of their mental illness), six were excluded because of staff shortages and time constraints and four over concerns about their psychological well-being, one prisoner was too physically unwell to be interviewed, one had been placed on a section of the Mental Health Act and another transferred to another prison. The sociodemographic and criminological characteristics of the excluded prisoners were not statistically different from those of participating prisoners (data available on request from the authors).

\section{Interviews}

Interviews were carried out with prisoners' written informed consent, and lasted between 30 and 90 minutes. A structured questionnaire, adapted from the Oxford Monitoring System for Attempted Suicide, ${ }^{27}$ was used to gather information about participants' sociodemographic profile and criminal history. Participants were also asked whether they had a history of in-patient or out-patient psychiatric treatment, whether they were receiving any medication and/or seeing a mental health professional (including a psychiatrist, psychologist, counsellor or community psychiatric nurse), and whether they had previously self-harmed without suicidal intent or attempted suicide (the distinction between self-harm and attempted suicide was based on self-reported intent). Where applicable, we gathered further information about a participant's self-harm history and about the circumstances surrounding her near-lethal act, including an assessment of suicidal intent using the Suicide Intent Scale. ${ }^{28}$ We also recorded whether participants were deemed to be 'at risk' (at the time of the near-lethal act in cases, and of the interview in controls) by asking whether they were on 'ACCT' (Assessment, Care in Custody and Teamwork), a procedure initiated in English and Welsh prisons when staff are concerned that a prisoner may harm him/herself (following an initial assessment, an individualised care plan is drawn up and reviewed regularly by a multidisciplinary team, and an ongoing record kept of significant events, conversation and observations).

Psychiatric disorders were assessed by means of the MINI, a short structured instrument that generates both ICD and DSM diagnoses. The MINI has been found to have good to very good kappa values (with only current drug dependence under 0.50), ${ }^{29}$ reliability (interrater and test-retest), and sensitivity and specificity indices, ${ }^{30-32}$ and has been used in previous prison research. ${ }^{33-35}$ Following concerns that the MINI may overdiagnose some psychiatric disorders in custodial settings, ${ }^{34}$ we made the following adjustments: a diagnosis of mania (current or lifetime) was only made when participants met criteria for elation/ expansiveness (i.e. irritable mood alone was insufficient to reach a diagnosis); a diagnosis of obsessive-compulsive disorder was dependent on meeting criteria for both obsessions and compulsions. Assessment of personality disorder in the MINI is restricted to antisocial personality disorder.

\section{Statistical analyses}

Differences between cases and controls were assessed using tests for categorical variables, and $t$-tests and Mann-Whitney $U$-tests for continuous ones. We then conducted analyses using logistic regression, with the outcome being near-lethal self-harm.

In addition to selecting controls in 10-year age bands, we further adjusted associations between psychiatric disorders and near-lethal self-harm for age (first model). We tested possible confounders (ethnicity, marital status, employment, educational qualification, index offence, remand status (i.e. whether awaiting trial or sentencing, as opposed to being a sentenced prisoner), sentence length greater than 18 months and having been in prison less than 30 days) by examining whether they were each independently associated with prisoners having made a near-lethal attempt in prison, and meeting criteria for a current psychiatric disorder. In adjusted models, all risk factors significantly associated with the presence of a current disorder were taken into account simultaneously. In the first model we adjusted for age, in the second model we adjusted for age and educational qualifications, and in the third model we also controlled for remand status.

All analyses were conducted using SPSS 15.0 for Windows, and a $95 \%(P<0.05)$ significance level was applied. In the results, denominators for some variables vary because of missing information.

\section{Results}

\section{Near-lethal incidents}

The majority of near-lethal incidents included in the study involved hanging $(28,47 \%)$ or ligaturing $(15,25 \%)$, with 
$9(15 \%)$ involving severe cuts and lacerations, 7 (12\%) overdoses, and $1(2 \%)$ self-induced diabetic coma. All but two incidents (97\%) had taken place in the prisoners' own cells, most of which were on normal wing location $(47,78 \%) ; 8(13 \%)$ were on intensive residential units, $4(7 \%)$ on segregation units and 1 $(2 \%)$ in the prison's healthcare centre.

Most prisoners in the near-lethal case group were deemed to be at 'risk' at the time of their act in that $53(88 \% v .0 \%$ in control prisoners) were on ACCT, the formal system for the care of prisoners at risk of suicide and self-harm in prisons in England and Wales. The mean suicide-intent score was relatively high $(18.9$, s.d. $=5.5)$ (the mean suicide intent score of females presenting to a general hospital in England following an incident of self-injury or self-poisoning was $9.2($ s.d. $=6.2)) .{ }^{36}$ Only three prisoners stated having carried out their act without the intent to die.

\section{Sample characteristics}

Table 1 shows details of sociodemographic, criminological and psychiatric history for prisoners involved in a near-lethal act (cases), and those in the control group. The majority of cases were White, single and under the age of 30 years $(38,63 \%)$. Nine prisoners (15\%) were aged between 18 and 20 years, 29 (49\%) were between the ages of 21 and 29 years, 19 (32\%) were aged between 30 and 39 years, 3 (5\%) were aged $40-49$ years and none was over 50 years old. These and other sociodemographic features did not differ significantly between cases and controls, except that more cases were of lower educational status. However, cases were more likely than controls to be on remand (awaiting trial or sentencing), to have been in their current prison less than 30 days, to have contact with a mental health professional and a history of in-patient and out-patient psychiatric treatment. In total 29 (48\%) cases had received psychiatric treatment within the past year, 19 $(32 \%)$ as out-patients, five $(8 \%)$ as in-patients, and five as both in-patients and out-patients.

Cases were also more likely than controls to have self-harmed with no suicidal intent in prison $(37 / 59(63 \%) v .10 / 60(17 \%)$, $\mathrm{OR}=8.41,95 \%$ CI $3.56-19.87, P<0.0001)$ and outside prison (39/59 (66\%) v. 13/60 (22\%), OR=7.05, 95\% CI 3.11-15.96, $P<0.0001$ ), and to have previously attempted suicide, both outside prison $(49 / 58(85 \%)$ v. $15 / 60$ (25\%), OR $=16.3,95 \% \mathrm{CI}$ $6.5-41.0, P<0.0001)$ and, to an even greater extent, in custody $(49 / 60 \quad(82 \%) \quad$ v. $2 / 60 \quad(3 \%), \quad \mathrm{OR}=129, \quad 95 \% \quad$ CI $27-611$, $P<0.0001$ ) (see Table 1 for comparisons of all self-harming behaviour, regardless of intent). A total of $50 \%$ of cases $(n=30)$ had attempted suicide in prison on five or more occasions, including 12 women (20\%) who had been hospitalised or transferred to the prison's healthcare wing at least five times following a suicide attempt. Most cases had also made repeated suicide attempts outside prison, with 41 (68\% v. 6, 10\% controls) having done so at least twice.

\section{Current psychiatric disorder}

All prisoners in the case group met criteria for at least one current psychiatric disorder (Table 2). All but four cases met criteria for at least two disorders and most had three or more disorders, including 13 women $(22 \%)$ who had six or more. In cases, the most prevalent diagnosis was major depression, followed by substance use disorder and post-traumatic stress disorder (PTSD). In controls, the most common diagnosis was substance use disorder, followed by major depression and PTSD. Differences between cases and controls were found in relation to most of the disorders where the data could be subjected to statistical comparison. The association between having a psychiatric diagnosis and having been involved in a near-lethal act was marked in relation to mood disorders, in particular major depression, and anxiety disorders, especially social anxiety, panic disorder and PTSD, but was not significant for eating disorders. The presence of a substance use disorder (within the previous year) was also unrelated to near-lethal self-harm, even in prisoners who had been in prison for less than a year (28/44 (63.6\%) v. 24/ $38(63.2 \%)$, age-adjusted $\mathrm{OR}=1.08,95 \%$ CI $0.43-2.70, P=0.874)$. Adjusting for sociodemographic and criminological variables did not significantly alter any of these findings. The risk of being involved in near-lethal self-harm in prison was greatest among prisoners who met criteria for two or more diagnoses.

\section{Lifetime psychiatric disorder}

Antisocial personality disorder was the most prevalent lifetime diagnosis in both cases and controls, and did not significantly

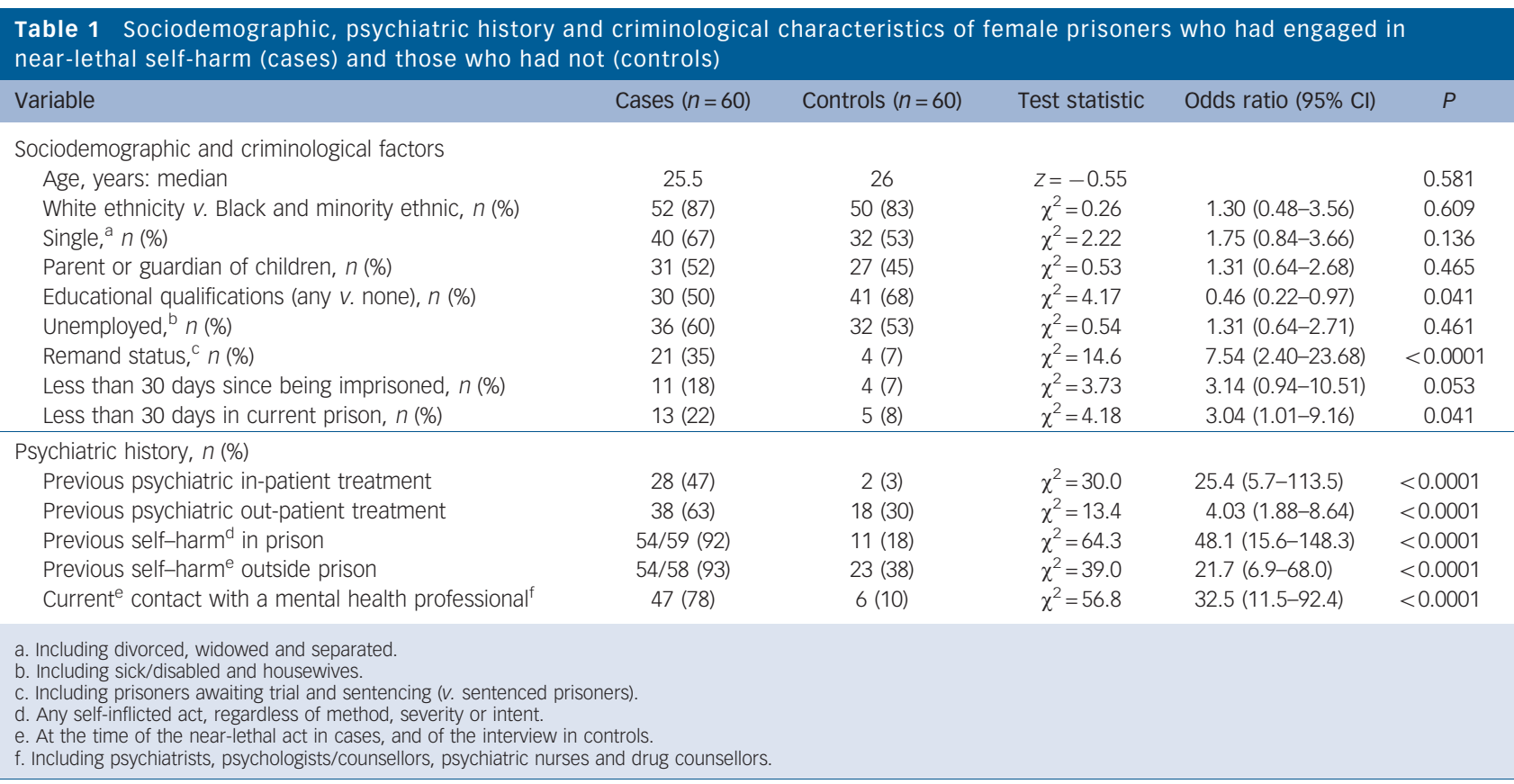




\begin{tabular}{|c|c|c|c|c|c|c|c|c|c|c|}
\hline \multirow[b]{2}{*}{ Disorder } & \multicolumn{2}{|c|}{ Cases $(n=60)$} & \multicolumn{2}{|c|}{ Controls $(n=60)$} & \multicolumn{2}{|c|}{ Model $1^{\mathrm{a}}$} & \multicolumn{2}{|c|}{ Model $2^{b}$} & \multicolumn{2}{|c|}{ Model $3^{c}$} \\
\hline & $n$ & (\%) & $n$ & (\%) & $\begin{array}{l}\text { Odds ratio } \\
(95 \% \mathrm{Cl})\end{array}$ & $P$ & $\begin{array}{l}\text { Odds ratio } \\
(95 \% \mathrm{Cl})\end{array}$ & $P$ & $\begin{array}{l}\text { Odds ratio } \\
(95 \% \mathrm{Cl})\end{array}$ & $P$ \\
\hline \multicolumn{11}{|l|}{ Mood disorders } \\
\hline Major depression & 52 & (87) & 13 & (22) & $23.7(9.0-62.3)$ & $<0.0001$ & $22.4(8.5-59.3)$ & $<0.0001$ & $19.3(7.2-52.2)$ & $<0.0001$ \\
\hline Melancholic depression & 41 & (68) & 9 & (15) & $12.7(5.1-31.7)$ & $<0.0001$ & $12.8(5.1-32.3)$ & $<0.0001$ & $10.5(4.1-27.0)$ & $<0.0001$ \\
\hline Mania $^{d}$ & 2 & (3) & 1 & (2) & & & & & & \\
\hline Any & 52 & (87) & 14 & (23) & $21.5(8.3-56.1)$ & $<0.0001$ & $20.5(7.8-53.7)$ & $<0.0001$ & $17.7(6.6-47.4)$ & $<0.0001$ \\
\hline \multicolumn{11}{|l|}{ Anxiety disorders } \\
\hline Panic & 20 & (33) & 5 & (8) & $5.56(1.90-16.27)$ & 0.002 & $5.21(1.76-15.38)$ & 0.003 & $4.78(1.56-14.65)$ & 0.006 \\
\hline Agoraphobia & 14 & (23) & 7 & (12) & $2.30(0.85-6.19)$ & 0.099 & $2.33(0.85-6.37)$ & 0.101 & $1.96(0.67-5.73)$ & 0.218 \\
\hline Social anxiety & 28 & (47) & 6 & (10) & $7.85(2.93-21.0)$ & $<0.0001$ & $7.82(2.88-21.20)$ & $<0.0001$ & $7.60(2.68-21.51)$ & $<0.0001$ \\
\hline Generalised anxiety & 5 & (8) & 8 & (13) & $0.59(0.18-1.91)$ & 0.374 & $0.59(0.18-1.95)$ & 0.383 & $0.61(0.17-2.16)$ & 0.443 \\
\hline $\mathrm{OCD}$ & 16 & (27) & 5 & (8) & $3.97(1.35-11.70)$ & 0.012 & $3.88(1.30-11.61)$ & 0.015 & $3.51(1.12-11.02)$ & 0.031 \\
\hline PTSD & 32 & (53) & 11 & (18) & 5.09 (2.22-11.70) & $<0.0001$ & $4.99(2.15-11.59)$ & $<0.0001$ & $5.73(2.34-14.00)$ & $<0.0001$ \\
\hline Any & 52 & (87) & 23 & (38) & $10.4(4.2-25.9)$ & $<0.0001$ & $10.2(4.1-25.5)$ & $<0.0001$ & $9.93(3.75-26.26)$ & $<0.0001$ \\
\hline \multicolumn{11}{|l|}{ Substance use disorders } \\
\hline Alcohol & 17 & (28) & 14 & (23) & $1.36(0.59-3.15)$ & 0.471 & $1.28(0.54-3.01)$ & 0.573 & $0.94(0.37-2.39)$ & 0.890 \\
\hline Drug & 27 & (45) & 25 & (42) & $1.17(0.56-2.42)$ & 0.676 & $1.12(0.54-2.36)$ & 0.758 & $0.83(0.37-1.87)$ & 0.658 \\
\hline Any & 34 & (57) & 30 & (50) & $1.36(0.65-2.82)$ & 0.415 & $1.18(0.55-2.51)$ & 0.669 & $0.96(0.43-2.15)$ & 0.923 \\
\hline \multicolumn{11}{|l|}{ Psychotic disorders } \\
\hline With mood disorder ${ }^{d}$ & 4 & (7) & 2 & (3) & & & & & & \\
\hline Without mood disorder & 9 & (15) & 2 & (3) & $5.09(1.05-24.69)$ & 0.043 & $4.16(0.84-20.70)$ & 0.081 & $5.56(1.07-28.77)$ & 0.041 \\
\hline Any & 13 & (22) & 4 & (7) & $3.91(1.19-12.81)$ & 0.025 & $3.51(1.05-11.70)$ & 0.041 & $3.49(1.00-12.12)$ & 0.050 \\
\hline \multicolumn{11}{|l|}{ Eating disorders } \\
\hline Anorexia ${ }^{\mathrm{d}, \mathrm{e}}$ & 1 & (2) & 0 & (0) & & & & & & \\
\hline Bulimia & 7 & (12) & 5 & (8) & $1.43(0.43-4.81)$ & 0.561 & $1.43(0.42-4.88)$ & 0.569 & $0.93(0.24-3.65)$ & 0.917 \\
\hline Any & 8 & (13) & 5 & (8) & $1.67(0.51-0.54)$ & 0.397 & $1.72(0.52-5.72)$ & 0.376 & $1.02(0.27-3.90)$ & 0.981 \\
\hline Any current disorder ${ }^{\mathrm{e}}$ & 60 & (100) & 40 & (67) & & & & & & \\
\hline $2+$ current disorders & 56 & (93) & 26 & (43) & $18.3(5.9-56.9)$ & $<0.0001$ & $18.4(5.8-58.3)$ & $<0.0001$ & $15.3(4.7-49.6)$ & $<0.0001$ \\
\hline $3+$ current disorders & 46 & (77) & 16 & (27) & $9.02(3.94-20.64)$ & $<0.0001$ & $8.75(3.79-20.23)$ & $<0.0001$ & $7.66(3.22-18.25)$ & $<0.0001$ \\
\hline $4+$ current disorders & 33 & (55) & 11 & (18) & $5.44(2.37-12.45)$ & $<0.0001$ & $5.28(2.28-12.22)$ & $<0.0001$ & $4.20(1.76-10.06)$ & 0.001 \\
\hline \multicolumn{11}{|c|}{$\begin{array}{l}\text { OCD, obsessive-compulsive disorder; PTSD, post-traumatic stress disorder. } \\
\text { a. Adjusted for age. } \\
\text { b. Adjusted for age and educational qualifications (any v. none). } \\
\text { C. Adjusted for age, educational qualifications and remand status (v. sentenced). } \\
\text { d. Tests not conducted owing to lack of statistical power. } \\
\text { e. Odds ratios undefined owing to } 100 \% \text { or } 0 \% \text { prevalence in one cell. }\end{array}$} \\
\hline
\end{tabular}

distinguish the two groups (Table 3). All but four cases meeting criteria for this disorder also suffered from current major depression and substance use disorder $(22 / 60$, (37\%) v. 8/60 $(13 \%)$, age-adjusted $\mathrm{OR}=4.41,95 \%$ CI $1.59-12.24, P=0.004)$.

All Axis I lifetime disorders were statistically associated with near-lethal self-harm, the strongest association being with recurrent depression. In adjusted models these associations remained unaltered. The presence of two or more psychiatric disorders was associated with greater risk than any single lifetime disorder.

\section{Psychiatric treatment at the time of the interview}

At the time of the interview, cases were more likely to have contact with a mental health professional and to be on medication, with the exception of opiates (Table 4). However, only one of the 13 cases not under psychiatric care at the time of their near-lethal attempt had since been reviewed by a psychiatrist. The majority of cases did not have regular contact with a mental health professional (only 25/58 (43\%) were being seen on a weekly basis). Following their near-lethal self-harm act, 4 prisoners (7\%) were under the care of three mental health professionals, 17 (29\%) were under the care of two, and most (26/59 (44\%)) had contact with one mental health professional, most often a psychiatric nurse.

One-third $(16 / 49(33 \%))$ of cases suffering from major depression were not receiving antidepressants at the time of the interview (information relative to three cases with depression was missing). Of these, 13 (81\%) were under the care of a mental health professional, but only $3(20 \%)$ were being seen on a regular weekly basis. Three cases (6\%) meeting criteria for depression were neither on antidepressants nor under the care of a mental health professional following their near-lethal attempt.

\section{Discussion}

Women prisoners who had recently engaged in near-lethal selfharm had significantly higher levels of psychiatric comorbidity than other women prisoners who had not carried out lethal self-harm attempts in prison. The strongest associations with near-lethal self-harm were with current depression, the presence of two or more diagnoses, a history of psychiatric contact and previous attempted suicide. The only tested diagnoses not associated with near-lethal self-harm were antisocial personality disorder, substance use disorders and eating disorders.

\section{Current psychiatric disorders}

All women in the near-lethal self-harm group met criteria for at least one current psychiatric disorder. This confirms the importance of psychiatric disorders as risk factors for suicidal behaviour in prisoners, especially women prisoners. ${ }^{11}$ The proportion of female prisoners with near-lethal self-harm having 


\begin{tabular}{|c|c|c|c|c|c|c|c|c|c|c|}
\hline \multirow[b]{2}{*}{ Disorder } & \multicolumn{2}{|c|}{ Cases $(n=60)$} & \multicolumn{2}{|c|}{ Controls $(n=60)$} & \multicolumn{2}{|c|}{ Model $1^{\mathrm{a}}$} & \multicolumn{2}{|c|}{ Model $2^{b}$} & \multicolumn{2}{|c|}{ Model $3^{c}$} \\
\hline & $n$ & (\%) & $n$ & (\%) & $\begin{array}{l}\text { Odds ratio } \\
(95 \% \mathrm{Cl})\end{array}$ & $P$ & $\begin{array}{l}\text { Odds ratio } \\
(95 \% \mathrm{Cl})\end{array}$ & $P$ & $\begin{array}{l}\text { Odds ratio } \\
(95 \% \mathrm{Cl})\end{array}$ & $P$ \\
\hline \multicolumn{11}{|l|}{ Mood disorders } \\
\hline Recurrent major depression & 21 & (35) & 4 & (7) & 7.50 (2.39-23.58) & 0.001 & $7.39(2.32-23.56)$ & 0.001 & $7.64(2.32-25.13)$ & 0.001 \\
\hline Mania & 20 & (33) & 10 & (17) & $2.62(1.09-6.30)$ & 0.031 & $2.67(1.09-6.53)$ & 0.032 & $3.24(1.25-8.44)$ & 0.016 \\
\hline Any & 30 & (50) & 13 & (22) & $3.78(1.69-8.48)$ & 0.001 & $3.83(1.68-8.71)$ & 0.001 & $4.51(1.85-10.96)$ & 0.001 \\
\hline \multicolumn{11}{|l|}{ Psychotic disorders } \\
\hline With mood disorder & 8 & (13) & 2 & (3) & $4.50(0.91-22.18)$ & 0.065 & $5.79(1.14-29.46)$ & 0.034 & $4.30(0.80-23.23)$ & 0.090 \\
\hline Without mood disorder & 12 & (20) & 4 & (7) & $3.48(1.05-11.51)$ & 0.041 & $3.02(0.90-10.20)$ & 0.075 & $3.38(0.95-12.01)$ & 0.060 \\
\hline Any & 20 & (33) & 6 & (10) & $4.50(1.65-12.22)$ & 0.003 & $4.48(1.62-12.36)$ & 0.004 & $4.15(1.45-11.89)$ & 0.008 \\
\hline Any lifetime Axis I disorder & 35 & (58) & 17 & (28) & $3.68(1.70-7.95)$ & 0.001 & $3.50(1.60-7.64)$ & 0.002 & $4.14(1.77-9.69)$ & 0.001 \\
\hline 2+ lifetime disorders & 21 & (35) & 2 & (3) & $16.0(3.5-72.2)$ & $<0.0001$ & $16.1(3.5-73.8)$ & $<0.0001$ & $17.1(3.6-80.8)$ & $<0.0001$ \\
\hline $3+$ lifetime disorders $^{\mathrm{d}}$ & 5 & (8) & 1 & (2) & & & & & & \\
\hline $4+$ lifetime disorders $^{\mathrm{d}}$ & 0 & (0) & 0 & (0) & & & & & & \\
\hline Antisocial personality disorder & 26 & (43) & 29 & (48) & $0.84(0.40-1.73)$ & 0.628 & $0.78(0.37-1.64)$ & 0.508 & $0.77(0.35-1.71)$ & 0.523 \\
\hline
\end{tabular}

\begin{tabular}{|c|c|c|c|c|c|c|c|}
\hline \multirow[b]{2}{*}{ Variable } & \multicolumn{2}{|c|}{ Cases $(n=60)^{a}$} & \multicolumn{2}{|c|}{ Controls $(n=60)^{a}$} & \multirow[b]{2}{*}{$\chi^{2}$} & \multirow[b]{2}{*}{ Odds ratio $(95 \% \mathrm{Cl})$} & \multirow[b]{2}{*}{$P$} \\
\hline & $n$ & (\%) & $n$ & (\%) & & & \\
\hline Seeing a mental health professional & 48 & (80) & 6 & (10) & 59.4 & $36.0(12.5-103.3)$ & $<0.0001$ \\
\hline Psychiatric nurse & 31 & (53) & 2 & (3) & 35.9 & $32.1(7.2-143.8)$ & $<0.0001$ \\
\hline Psychiatrist $^{\mathrm{b}}$ & 28 & (48) & 0 & (0) & 37.2 & & $<0.0001$ \\
\hline Psychologist/counsellor & 12 & (20) & 3 & (5) & 6.35 & $4.85(1.29-13.68)$ & 0.012 \\
\hline Drug counsellor ${ }^{\mathrm{C}}$ & 1 & (2) & 1 & (2) & & & \\
\hline Medication & 56 & (93) & 30 & (50) & 27.7 & $14.0(4.5-43.5)$ & $<0.0001$ \\
\hline Physical medication & $22 / 59$ & (37) & 13 & (22) & 3.50 & $2.15(0.96-4.83)$ & 0.061 \\
\hline Opiates & $12 / 57$ & (21) & 10 & (17) & 0.37 & $1.33(0.53-3.38)$ & 0.544 \\
\hline Any psychotropic medication & 51 & (85) & 18 & (30) & 37.1 & $13.2(5.4-32.5)$ & $<0.0001$ \\
\hline Antidepressants & $38 / 57$ & (67) & 17 & (28) & 17.2 & $5.06(2.30-11.11)$ & $<0.0001$ \\
\hline Mood stabilisers $\mathrm{b}$ & $6 / 56$ & (11) & 0 & (0) & 6.78 & & 0.009 \\
\hline Benzodiazepines and sedatives & $22 / 57$ & (39) & 4 & (7) & 17.2 & $8.80(2.80-27.68)$ & $<0.0001$ \\
\hline Major tranquillisers ${ }^{\mathrm{b}}$ & $24 / 59$ & (41) & 0 & (0) & 30.6 & & $<0.0001$ \\
\hline
\end{tabular}

a psychiatric diagnosis was greater than previously reported in male-only and predominantly male prisoner samples of suicides and suicide attempters. ${ }^{12,37}$ All but four cases had two or more disorders, and most met criteria for at least three current disorders. Whereas the majority of controls also had at least one current psychiatric disorder, comorbidity was significantly less prevalent in this group. Research in the community has found that psychiatric comorbidity is common in female suicides. ${ }^{38}$

Comparisons on specific diagnoses showed cases to be disproportionally affected by mood, anxiety and psychotic disorders. Differences between the two groups were particularly marked in relation to depression, both current and recurrent, which is consistent with the existing literature on risk factors for suicide, both in prison ${ }^{39}$ and in the general population. ${ }^{40}$

As in community suicide studies, ${ }^{9,10}$ current depression was also the most prevalent diagnosis in near-lethal cases (87\%), followed by substance use disorder (57\%). The latter has previously - and repeatedly - been reported to be the most common diagnosis in men and women who have died by suicide in prison. ${ }^{11,41-43}$ However, the prevalence of alcohol- and drugrelated problems did not differ in cases and controls, being by far the most prevalent disorders in the latter group. This is in contrast with the findings of previous case-control studies in the community ${ }^{44}$ and in male-only and predominantly male prisoner samples, ${ }^{12,13}$ but consistent with data from the Office for National Statistics study of non-fatal suicidal behaviour among prisoners, in which prevalence estimates were reported by gender. ${ }^{45}$

It is also notable that PTSD, which has received little attention in previous research on suicidal behaviour and mental disorders in prisons, ${ }^{46}$ was the third most prevalent diagnosis in female prisoners who had engaged in near-lethal self-harm, being diagnosed in approximately half. Along with other anxiety disorders (especially social anxiety and panic disorder) and psychotic disorder (without mood disorder), PTSD was also one of the diagnoses most strongly associated with near-fatal selfharm. In contrast, eating disorders were not significantly associated with the risk of a near-lethal attempt, despite being strong risk factors for suicide in the community, especially 
anorexia. ${ }^{47}$ In view of the relatively low prevalence of eating disorders in prisoners, ${ }^{6}$ this finding should be viewed cautiously as the study may have been underpowered to investigate it adequately.

\section{Lifetime psychiatric disorders and historical factors}

Although current psychiatric disorders were more strongly associated with the likelihood of a near-lethal attempt than lifetime diagnoses, prevalence of previous disorders also distinguished the two groups, as found in a case-control study of male prisoners who had attempted suicide. ${ }^{37}$ The majority of cases met criteria for at least one lifetime diagnosis, with recurrent depression, mania and psychotic disorders having similar prevalence rates (33-35\%). Unlike all Axis I disorders, antisocial personality disorder was not significantly associated with nearlethal self-harm, despite being the most common lifetime disorder among the case group (43\%). Previous research has also shown that antisocial personality disorder is not associated with suicidal behaviour in prisoners, ${ }^{16,45}$ despite being a major risk factor for suicide in the community. ${ }^{48,49}$ As with substance use disorder, this discrepancy appears to be a result of the high levels of morbidity in prisoner controls compared with the general population. Even in relation to disorders that were associated with near-lethal selfharm, prevalence rates in controls were higher than those reported in male prisoners, and in men and women in the general population. $^{5-7}$

Our study suggests that women who nearly died following a suicide attempt in prison are almost twice as likely as general population suicides to have been in recent contact with mental health services. ${ }^{50}$ In total $48 \%$ of cases had received psychiatric treatment in the year prior to their attempt, and over threequarters were under the care of a mental health professional at the time of their near-lethal act. In part, this may reflect the high levels of psychiatric treatment in women offenders. ${ }^{51}$ However, it is notable that controls were significantly less likely to have a history of psychiatric treatment. Research investigating the characteristics of prisoners (mostly men) who have died by suicide and a recent study of self-harming behaviour in women prisoners had similar findings. ${ }^{12,13,15}$

Cases were also more likely than controls to have previously self-harmed and/or attempted suicide, and to have done so repeatedly, both in prison and outside. All but one case had a history of self-harm, with or without suicidal intent, and most had previously attempted suicide in prison. A history of attempted suicide is a known risk factor for suicide in the community, ${ }^{52}$ and was recently found to be the clinical variable most strongly associated with the risk of suicide in prisoners. ${ }^{14}$ Our findings suggest that this is particularly the case for previous attempted suicide in prison, even though the risk associated with previous attempts outside prison was also high.

\section{Strengths and limitations}

Investigating cases of near-lethal self-harm is unusual in prison research on suicidal behaviour. ${ }^{23,26}$ Yet it provides an opportunity to study in-depth many aspects of risk and process associated with the behaviour. Although the extent to which the individuals identified using our criteria approximate actual suicides can be questioned, this approach is likely to further understanding of suicide, and of near-lethal self-harm itself. Owing to its greater prevalence, the latter is perhaps a greater burden on prison and National Health Service resources than prisoner suicide. This may be especially the case in the female prison population, as its relatively small size (approximately $5 \%$ of the overall prison population) means that suicides are low in absolute numbers, despite being high in rate.
The use of self-reported data, although having many advantages, is open to problems of recall bias, especially for earlier disorders and behaviour. Although prison and clinical records may corroborate the information provided (we did not have access to these), the quality of such records can be variable. ${ }^{24,25}$ Nevertheless, there is no reason to assume that the accounts of cases were more or less biased than those of controls, and that therefore the level and direction of differences were affected. Previous research suggests that case-control comparisons based on analyses of official records have greater problems with biased and missing data, because the personal files of controls tend to contain less information than those of cases. ${ }^{12}$

As this is, to our knowledge, the first case-control study of near-lethal self-harm in women prisoners, we cannot directly compare our findings with those of earlier research. Methodological and definitional differences also preclude direct comparisons with previous research on suicide and attempted suicide in male prisoners (we will be reporting subsequently on a parallel study of near-lethal self-harm in male prisoners). Nevertheless, our control group appeared to be representative of women prisoners, with the prevalence of depression (22\%), anxiety $(38 \%)$, psychosis $(10 \%)$, antisocial personality disorder $(48 \%)$ and substance use disorder $(50 \%)$ being comparable to previous estimates in the female prison population and in women prisoners who have never attempted suicide (in prison or outside)..$^{5,7,53}$ The inclusion of all ten closed female prison establishments in England and Wales further enhances the generalisability of the study's findings.

We used the MINI for assessment of Axis I and Axis II diagnoses, the latter being, however, restricted in this schedule to antisocial personality disorder. Further work is needed to systematically examine the role of other personality disorders in prisoners' suicidal behaviour, preferably using longitudinal repeated measures and informant ratings. ${ }^{54}$ In particular the association with borderline personality disorder may be relevant. ${ }^{55,56}$

This study was cross-sectional. Longitudinal studies are needed to confirm that associations with near-lethal self-harm found in this study do truly represent risk factors. However, we have identified some major factors that appear to be associated with near-lethal self-harm and that are therefore likely to be associated with suicide.

\section{Implications}

Previous authors have suggested that comprehensive suicide prevention programmes might reduce suicides and suicide attempts in prisons by improving detection and management of risk. ${ }^{57-61}$ This study underscores calls for comprehensive screening of prisoners' suicide risk and mental health needs, possibly with the aid of a structured 'suicide checklist.'.5,62,63 Based on our findings, screening instruments should include assessment of individuals' history of psychiatric contact and diagnosis, past self-harming behaviour and current symptoms of psychiatric disorders, especially depression and anxiety disorders. As nearlethal suicide attempters were significantly more likely than controls to have multiple than single psychiatric diagnoses, efficient detection of co-occurring disorders should also be regarded as an important priority. In individuals with comorbidity, symptoms of one disorder may mask or exacerbate symptoms of comorbid disorders, in turn potentially complicating treatment in an already difficult-to-treat group. ${ }^{64}$ Screening should not only take place at intake, but also during incarceration, especially if a prisoner's circumstances or condition change.

Even when screening is ongoing and comprehensive, identifying the risk of an event as rare as suicide is problematic. 
It is encouraging that a formal care plan was in place for the majority of near-lethal cases at the time of their attempt, and that none of the control prisoners were identified as being at risk, despite many of them also suffering from poor mental health. Previous research has also reported better detection of risk in women prisoners who have died by suicide compared with male prisoners. ${ }^{11}$ On the other hand, the findings that most cases had carried out their near-lethal attempt despite having been identified as 'at risk', and were receiving psychiatric treatment at the time of the act, also suggest high levels of unmet need. The extent to which their needs were being met following their near-lethal attempts may also be questioned. Although most cases were receiving antidepressants and/or other psychotropic medication at the time of the interview, the potential complexity of their needs suggests that consideration be given to interventions incorporating both pharmacological and psychological treatment.

Further research should chart the range, use and effectiveness of interventions available to women prisoners, and inform improvements to the treatment of psychiatric disorders, especially depression, in this group. Ideally, the development and evaluation of interventions should be guided by comprehensive assessment of needs. In this context, consideration should be given to the high levels of psychiatric comorbidity in women prisoners, and its co-occurence with other health, criminological and psychosocial problems associated with the risk of suicide. In view of women prisoners' multiple and complex needs, and greater vulnerability to the pressures of imprisonment, ${ }^{65}$ future work should consider whether certain aspects of the detection, management and prevention of suicidal behaviour are particularly pertinent to female prisoners.

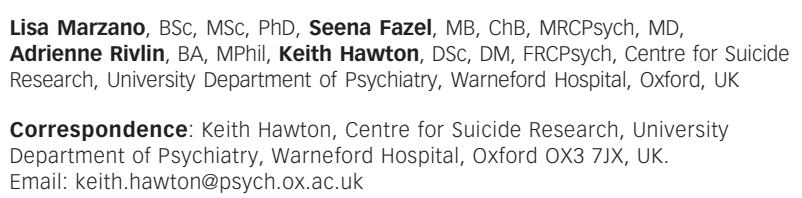

\section{Appendix}

\section{Criteria for the identification of 'near-lethal' cases}

Method

\section{Inclusion criteria}

Attempted hanging Unconscious after attempting to hang or use a ligature Ligature use Self-strangulation

\section{or not unconscious but:}

(a) witnessed in suspension or using a ligature and physical evidence of asphyxiation; or (b) physical evidence of suspension or using a ligature

Self-asphyxiation Suffocation Witnessed self-asphyxiating, or any other physical evidence of self-asphyxiation

Cutting

Stabbing

Wound aggravation

or insertion

Sustained a puncture wound penetrating body cavity or major organ, or lacerations that damaged or severed tendons, arteries or large veins, or came very close to doing so

Ingesting, inhaling, injecting

\section{(a) Level of} consciousness

(b) Biochemical abnormalities

(a) Objective evidence of altered level of consciousness, or unconscious at presentation or prior to medical facility

(b) Transferred or admitted to a prison healthcare unit, any outside hospital or accident and emergency department

Jumping

Witnessed jumping or any physical evidence of having jumped from a considerable height, likely to have led to serious injury

Other Determined on a case-by-case basis

(e.g. setting fire to self)

\section{Funding}

The study was funded by the NHS Forensic Mental Health R\&D Programme. K.H. is supported by the National Institute for Health Research, for which he is a senior investigator, and Oxfordshire and Buckinghamshire Mental Health NHS Foundation Trust.

\section{Acknowledgements}

We are grateful to Pat Baskerville, Debra Baldwin, Tunde Adeniji and Jenny Rees of the Ministry of Justice Safer Custody and Offender Policy Group for their operational support and advice, Dr Mary Piper of the Department of Health, Dr Jo Borrill and Jo Paton for their assistance with the study, Adam Spriggs of the Ministry of Justice for providing control data, and all Area and Local Suicide Prevention Coordinators who helped with recruitment for the study. We also thank Dr Julia Cartwright of Oxfordshire and Buckinghamshire Mental Health NHS Foundation Trust for providing additional clinical supervision, and Karen Smith of the Centre for Statistics in Medicine for statistical assistance.

\section{References}

1 Dalton V. Prison deaths 1980-1997: national overview and state trends. Trends Issues Crime Crim Justice 1998; 81: 1-8.

2 Kariminia A, Law MG, Butler TG, Corben SP, Levy MH, Kaldor JM, et al. Factors associated with mortality in a cohort of Australian prisoners. Eur J Epidemiol 2007; 22: 417-28.

3 Fazel S, Benning R. Natural deaths in male prisoners: a 20-year mortality study. Eur J Public Health 2006; 16: 441-4.

4 Fazel S, Benning R. Suicides in female prisoners in England and Wales, 1978-2004. Br J Psychiatry 2009; 194: 183-4.

5 Fazel S, Danesh J. Serious mental disorder among 23000 prisoners: a systematic review of 62 surveys. Lancet 2002; 359: 545-50.

6 Maden T, Swinton M, Gunn J. Psychiatric disorder in women serving a prison sentence. Br J Psychiatry 1994; 164: 44-54.

7 O'Brien M, Mortimer L, Singleton N, Meltzer H. Psychiatric morbidity among women prisoners in England and Wales. Int Rev Psychiatry 2003; 15: 153-7.

8 Gore SM. Suicide in prisons. Reflection of the communities served, or exacerbated risk? Br J Psychiatry 1999; 175: 50-5.

9 Cavanagh JTO, Carson AJ, Sharpe M, Lawrie SM. Psychological autopsy studies of suicide: a systematic review. Psychol Med 2003; 33: 395-405.

10 Hawton K, Van Heeringen K. Suicide. Lancet 2009; 373: 1372-81.

11 Mackenzie N, Oram C, Borrill J. Self-inflicted deaths of women in custody. Br J Forensic Pract 2003; 5: 27-35.

12 Fruehwald $S$, Matschnig $T$, Koenig $F$, Bauer $P$, Frottier $P$. Suicide in custody: case-control study. Br J Psychiatry 2004; 185: 494-8.

13 Blaauw E, Kerkhof JFM, Hayes LM. Demographic, criminal and psychiatric factors related to inmate suicide. Suicide Life Threat Behav 2005; 35: 63-75.

14 Fazel S, Cartwright J, Norman-Nott A, Hawton K. Suicide in prisoners: a systematic review of risk factors. J Clin Psychiatry 2008; 69: 1721-31.

15 Völlm BA, Dolan MC. Self-harm among UK female prisoners: a cross-sectional study. J Forensic Psychiatry Psychol 2009; 20: 741-51.

16 Jenkins R, Bhugra $D$, Meltzer $H$, Singleton $N$, Bebbington $P$, Brugha $T$, et al. Psychiatric and social aspects of suicidal behaviour in prisons. Psychol Med 2005; 35: 257-69.

17 Devon RC, Abram KM, Mcclelland GM, Teplin LA. Suicidal ideation and behaviour among women in jail. J Contemp Crim Justice 2003; 19: 65-80.

18 Offender Management and Sentencing Analytical Services (OMSAS). Offender Management Safer Custody Statistics, February/March 2010. Ministry of Justice OMSAS, 2010.

19 Borrill J, Rachel B, Richard A, Sarah M, Daniel B, Tim W, et al. Patterns of selfharm and attempted suicide among white and black/mixed race female prisoners. Crim Behav Ment Health 2003; 13: 229-40.

20 Moscicki EK. Epidemiology of suicide behavior. Suicide Life Threat Behav 1995; 25: 22-35.

21 Douglas J, Cooper J, Amos T, Webb R, Guthrie E, Appleby L. "Near-fatal" deliberate self-harm: characteristics, prevention and implications for the prevention of suicide. J Affective Dis 2004; 79: 263-8.

22 Rosen DH. The serious suicide attempt: five year follow-up study of 886 patients. JAMA 1976; 235: 2105-9.

23 Marzano L, Rivlin A, Fazel S, Hawton K. Interviewing survivors of near-lethal self-harm: a novel approach for investigating suicide amongst prisoners. J Forensic Legal Med 2009; 16: 152-5.

24 Liebling A. Suicides in Prison. Routledge, 1992.

25 Crighton D. Suicide in prisons: a critique of UK research. In Suicide in Prisons (eds G Towl, L Snow, M McHugh). Blackwell, 2002. 
26 Borrill J, Snow L, Medlicott D, Teers R, Paton J. Learning from near misses: interviews with women who survived an incident of severe self-harm. Howard League J 2005; 44: 57-69.

27 Hawton K, Harriss L, Hall S, Simkin S, Bale E, Bond A. Deliberate self-harm in Oxford, 1990-2000: a time of change in patient characteristics. Psychol Med 2003; 33: 987-96.

28 Beck AT, Schuyler D, Herman J. Development of Suicidal Intent Scales. In The Prediction of Suicide (AT Beck, H Resnik, DJ Lettieri): 45-6. Charles, 1974.

29 Spitzer RL, Williams JBW, Gibbon M, First MB. Structured Clinical Interview for DSM-III-R. American Psychiatric Press, 1990.

30 Amorim $P$, Lecrubier $Y$, Weiller E, Hergueta T, Sheehan D. DSM-III-R psychotic disorders: procedural validity of the Mini International Neuropsychiatric Interview (MINI). Concordance and causes for discordance with the CIDI. Eur Psychiatry 1998; 13: 26-34.

31 Lecrubier Y, Sheehan DV, Weiller E, Amorim P, Bonora I, Sheehan KH, et al. The Mini International Neuropsychiatric Interview (MINI). A short diagnostic structured interview: reliability and validity according to the CIDI. Eur Psychiatry 1997; 12: 224-31.

32 Sheehan DV, Lecrubier $\mathrm{Y}$, Sheehan $\mathrm{KH}$, Janavs J, Weiller E, Keskiner A, et al. The validity of the Mini International Neuropsychiatric Interview (MINI) according to the SCID-P and its reliability. Eur Psychiatry 1997; 12: 232-41.

33 Black DW, Arndt S, Hale N, Rogerson R. Use of the Mini International Neuropsychiatric Interview (MINI) as a screening tool in prisons: results of a preliminary study. J Am Acad Psychiatry Law 2004; 32: 158-62.

34 Gunter TD, Arndt S, Wenman G, Allen J, Loveless P, Sieleni B, et al. Frequency of mental and addictive disorders among 320 men and women entering the Iowa Prison System: use of the MINI-Plus. J Am Acad Psychiatry Law 2008; 36: 27-34.

35 Sarchiapone M, Jovanoviæ N, Roy A, Podlesek A, Carli V, Amore M, et al. Relations of psychological characteristics to suicide behaviour: results from a large sample of male prisoners. Pers Ind Dif 2009; 47: 250-5.

36 Harriss L, Hawton K, Zahl D. Value of measuring suicidal intent in the assessment of people attending hospital following self-poisoning or selfinjury. Br J Psychiatry 2005; 186: 60-6.

37 Sarchiapone M, Carli V, Di Giannantonio M, Roy A. Risk factors for attempting suicide in prisoners. Suicide Life Threat Behav 2009; 39: 343-50.

38 Foster T, Gillespie K, Mcclelland R. Mental disorders and suicide in Northern Ireland. Br J Psychiatry 1997; 170: 447-52.

39 Lupei RA. Jail Suicides: Demographic and Behavioural Factors Postdictive of the Completed Act. Oklahoma State University, 1981.

40 Lonnqvist J, Hawton K, van Heeringen K. Psychiatric aspects of suicidal behaviour: depression. In The International Handbook of Suicide and Attempted Suicide: 107-120. Wiley, 2000.

41 Backett SA. Suicides in Scottish prisons. Br J Psychiatry 1987; 151: 218-21.

42 Dooley E. Prison suicide in England and Wales, 1972-87. Br J Psychiatry 1990 156: $40-5$.

43 Shaw J, Baker D, Hunt IM, Moloney A, Appleby L. Suicide by prisoners. Br J Psychiatry 2004; 184: 263-7.

44 Conner KR, Duberstein PR. Predisposing and precipitating factors for suicide among alcoholics. Empirical review and conceptual integration. Alcohol Clin Exp Res 2004; 28: 6S-17S.

45 Meltzer H, Jenkins R, Singleton S, Charlton J, Yar M. Non-fatal Suicidal Behaviour among Prisoners. Office for National Statistics, 1999.
46 Goff A, Rose E, Rose S, Purves D. Does PTSD occur in sentenced prison populations? A systematic literature review. Crim Behav Ment Health 2007; 17: $152-62$

47 Bridge JA, Goldstein TR, Brent DA. Adolescent suicide and suicidal behavior. J Child Psychol Psychiatry 2006; 47: 372-94.

48 Duberstein PR, Conwell Y. Personality disorders and completed suicide: a methodological and conceptual review. Clinical Psychol Sci Pract 1997; 4: 359-76.

49 Linehan MM, Rizvi SL, Welch SS, Page B, Hawton K, Van Heeringen K. Psychiatric aspects of suicidal behaviour: personality disorders. In The International Handbook of Suicide and Attempted Suicide: 147-78. Wiley, 2000.

50 Appleby L, Shaw JAT, McDonnell R, Harris C, McCann K, Kiernan K, et al. Suicide within 12 months of contact with mental health services: national clinical survey. BMJ 1999; 318: 1235-9.

51 Maden A, Swinton M, Gunn J. A criminological and psychiatric survey of women serving a prison sentence. Br J Criminol 1994; 34: 72-91.

52 Hawton K, Fagg J. Suicide, and other causes of death, following attempted suicide. Br J Psychiatry 1988; 152: 359-66.

53 Warren Jl, Burnette M, South SC, Chauhan P, Bale R, Friend R. Personality disorders and violence among female prison inmates. J Am Acad Psychiatry Law 2002; 30: 502-9.

54 Tyrer $\mathrm{P}$, Coombs N, Ibrahimi F, Mathilakath A, Bajaj P, Ranger M, et al. Critical developments in the assessment of personality disorder. Br J Psychiatry 2007; 190: s51-9.

55 Coid J, Wilkins J, Coid B, Everitt B. Self-mutilation in female remanded prisoners II: a cluster analytic approach towards identification of a behavioural syndrome. Crim Behav Ment Health 1992; 2: 1-14.

56 Lohner J, Konrad N. Risk factors for self-injurious behaviour in custody: problems of definition and prediction. Int J Prisoner Health 2007; 3: 135-61.

57 Cox JF, Morschauser PC. A solution to the problem of jail suicide. Crisis 1997; 18: $178-84$.

58 Felthous AR. Preventing jailhouse suicides. Bull Am Acad Psychiatry Law 1994; 22: 477-87.

59 White TW, Schimmel DJ. Suicide prevention in federal prisons: a successful five-step program. In Prison suicide: An Overview and Guide to Prevention (ed AJ Hayes): 46-57. Department of Justice, National Institute of Correction, 1995.

60 Gallagher CA, Dobrin A. The association between suicide screening practices and attempts requiring emergency care in juvenile justice facilities. J Am Acad Child Adolescent Psychiatry 2005; 44: 485-93.

61 Bird SM. Changes in male suicides in Scottish prisons: 10-year study. Br J Psychiatry 2008; 192: 446-9.

62 Frottier $P$, Koenig $F$, Seyringer $M$, Matschnig $T$, Fruehwald $S$. The distillation of "VISCI": towards a better identification of suicidal inmates. Suicide Life Threat Behav 2009; 39: 376-84.

63 Konrad N, Daigle MS, Daniel AE, Dear GE, Frottier P, Hayes LM, et al. Preventing suicide in prisons, part I. Recommendations from the International Association for Suicide Prevention Task Force on Suicide in Prisons. Crisis 2007; 28: 113-21.

64 Abram KM, Teplin LA. Co-occuring disorders among mentally ill jail detainees: implications for public policy. Am Psychologist 1991; 46: 1036-45.

65 Corston J. The Corston Report: A Review of Women with Particular Vulnerabilities in the Criminal Justice System. Home Office, 2007. 